\title{
New approaches and opportunities in the treatment of chronic prostatitis associated with sexually transmitted infections
}

\begin{abstract}
Background: The aim of this study was to assess the efficacy and safety of pulse dosed vacuum gradient therapy in the treatment of the patients with chronic prostatitis associated with sexually transmitted infections (STIs).
\end{abstract}

Material and methods: The study was approved by Local Ethics Committee of Kazan State Medical University (registration №3, 24 March 2015). In this randomized controlled study men with clinically, laboratory and instrumentally verified diagnosis of chronic prostatitis associated with STIs were enrolled between September 2014 and May 2016 and divided into two groups: the main and the comparison group. The patients in both group were administered the same systemic treatment, however, the main group patients had additionally got the method of pulse dose vacuum gradient therapy.

Results: A total of 145 men were included: 105 patients in the main group and 40 patients in the comparison group. The effectiveness of the etiological cure of patients in the main group was $99.1 \%$, while in the control group it composed $92.5 \%$. Hyperechoic zones according to transrectal ultrasound investigation detected in the main group patients were almost three times less in the control after the performed treatment. The ultrasound dopplerographic examination showed the next results: the values of vascular density in the main group were higher by $0.7 \pm 0.02$ and amounted to $1.57 \pm 0.03$, while in the control group it remained practically unchanged and stopped at the level of $0.85 \pm 0.08$ vessels per $1 \mathrm{sq} . \mathrm{cm}$. The concentration of doxycycline monohydrate in the prostatic secretion in the main group increased significantly from $1.4 \pm 0.02 \mu \mathrm{g} / \mathrm{ml}$ to $2.0 \pm 0.1 \mu \mathrm{g} / \mathrm{ml}$, i.e, by $0.6 \pm 0.01 \mu \mathrm{g} / \mathrm{ml}$, while in the control group it remained practically at the baseline level of $1.4 \pm 0.08 \mu \mathrm{g} / \mathrm{ml}$.

Conclusion: the use of pulse dosed vacuum gradient therapy as an additional method in the complex treatment of chronic prostatitis associated with sexually transmitted infections is safe and much more effective in comparison with the standard therapy.

Keywords: Chronic prostatitis, sexually transmitted infections, reproductive system, infertility.
Volume 6 Issue 3 - 2018

\author{
Azat R Abdrakhmanov, ${ }^{1,2}$ Rasim M \\ Abdrakhmanov ${ }^{3}$ \\ 'Research Laboratory of Reproductive Health, Kazan Federal \\ University, Russia \\ ${ }^{2}$ Center of Men`s Health, University Clinic Kazan, Kazan Federal \\ University, Russia \\ ${ }^{3}$ Dermatovenerology Department, Kazan State Medical \\ University, Russia
}

Correspondence: Azat R Abdrakhmanov, 420105, Russian Federation, Kazan, 20 Shchorsa str, Russia, Tel +79033 I40372, Email dr.abdrakhmanov.azat@yandex.ru

Received: February 26, 2018 | Published: May 22, 2018

\section{Introduction}

The significance of the problem of effective therapy of chronic prostatitis, associated with sexually transmitted infections, is conditioned primarily to the fact that the highest incidence rate of this pathology is registered in individuals not older than 45 years. Thus, men suffer in the most active period of life. ${ }^{1}$ The patients with 20-45 years old, the reduction of their copulative and reproductive functions, the persistent and prolonged course of the disease not succumbed to the traditional methods of treatment; short periods of remission allow us to consider chronic prostatitis as a serious medical and social problem. $^{2}$

It should be also noted that one of the main causes of impaired fertility are infectious diseases of the organs of the male reproductive system. ${ }^{3}$ Moreover, the proportion of male infertility associated with various inflammatory diseases of the pelvic organs, including chronic prostatitis, constitutes almost the half of the cases in the structure of infertile marriage, and recently there has been a tendency to its constant growth. The main factor in the continued increase of male infertility proportion is the belated and/or irrational treatment of STIs. Thus, infections of the male and female genitourinary system pose a threat to reproductive disorders. ${ }^{2}$

The poor penetration of medications into the infiltrativesclerotically altered areas of the inflamed prostate is another important problem. Traditional methods of treatment of chronic prostatitis associated with STIs in most cases do not allow achieving the necessary therapeutic concentration of medications. ${ }^{4}$ Its share in the low efficacy of chronic prostatitis treatment is made by significant changes in the microcirculatory bed in altered prostate tissues, characterized by a slowing of blood flow velocity, aggregation, and stasis of blood elements. ${ }^{5}$ In this regard, we evaluated the effectiveness of the method of pulse dosed vacuum gradient therapy (VGT) as one of the variants of targeted medications delivery, as well as the restoration of infiltrative-altered prostate tissue during the treatment of chronic prostatitis associated with sexually transmitted infections.

\section{Materials and methods}

The principle of the proposed method is to create passive artificial forced hyperemia, which creates an increased blood saturation of the prostate tissue and, accordingly, improves the medications targeted delivery to the affected prostate. Thus, the beneficial effect of pulse 
dosed vacuum gradient therapy on damaged tissues is associated with a significantly increased blood flow due to a decrease in the external pressure on the blood vessels, which leads to their expansion and the opening of a large number of functioning capillaries.

All patients submitted their written informed consent for participation in the study. This study was approved by Local Ethics Committee of Kazan State Medical University, Kazan, Russian Federation. We examined 145 patients with laboratory and instrumentally confirmed diagnosis of chronic prostatitis, associated STIs, which were randomly divided into two groups: the main ( $\mathrm{n}=105$ patients) and the comparison group ( $\mathrm{n}=40$ patients). Diagnosis and management of patients in both groups was performed according to clinical guidelines for managing patients with sexually transmitted infections and urogenital infections of Russian Society of Dermatovenereologists and Cosmetologists.

In the etiologic diagnosis of STIs the following methods were used: microscopic examination of patient's biomaterial (secretion of prostate), molecular-biological research methods for the determination of specific DNA and/or RNA fragments with the use of test systems and their expendable materials approved in Russian Federation, microbiological examination (in the presence of indications), cytomorphological examination (if it was necessary).

The prostate secretion was collected after the preliminary urination act. To minimize contamination of the prostate secretion with the contents of the mucous membrane of the urethra collection of material from the prostate was produced in the following way:

a) Introduced a disposable sterile catheter with the syringe inserted in its free area to the prostatic part of the urethra.

b) Then massage of prostate gland was performed. At the same time, a slight negative pressure was created in the distal end of the catheter with an inserted syringe in the catheter located in the prostatic part of the urethra, and the prostate secretion through the catheter ended up in the syringe due to pressure difference.

The following main clinical methods were used in the diagnosis of chronic bacterial prostatitis: palpatory examination of the prostate, microscopic analysis of the secretion of the prostate, irrigative fiberoptic digital video endoscopy, transrectal ultrasound examination with dopplerography. Transrectal ultrasound examination let us to define the sharpness and evenness of the prostate gland contours, structure, features of its echogenicity, changes in size, revealed pathological formations. Doppler ultrasound method was used to evaluate the dynamics of blood supply of the prostate gland. The following parameters of the Doppler ultrasound study were assessed: vascular density (vessel per sq.cm); peak systolic blood flow velocity $(\mathrm{cm} / \mathrm{sec})$; mean linear velocity of blood flow $(\mathrm{cm} / \mathrm{sec})$.

Determination of the medication concentration in the blood plasma and secretion of the prostate gland was made strictly at a certain time after taking the medication in a daily dose. The thinlayer chromatography method was used, taking into account its high sensitivity, the accuracy of measurements and the relatively low cost. The beneficial effect of VGT on damaged tissues is associated with a significant increase in organ blood flow by reducing external pressure on the blood vessels. It leads to their dilatation and the opening of a large number of functioning capillaries, so it improves blood flow in the lesion focus. Penis placed in pressure mini chamber is under the influence of pressure less than atmospheric at $150-300 \mathrm{~mm} \mathrm{Hg}$.
The decrease of atmospheric pressure in the mini chamber causes an increase of arterial inflow to the penis and other organs of the reproductive system, in particular, to the prostate. Due to the pressure difference and, consequently, the enhanced blood flow, the volume of local blood flow increases and, accordingly, there is a more intensive diffusion of medications from the blood into the prostate tissue affected by pathological process.

The general systemic standard treatment in both groups was carried out in accordance with clinical guidelines for managing patients with sexually transmitted infections and urogenital infections developed by the Russian Society of Dermatovenereologists and Cosmetologists (2015). In the main group along with standard treatment were additionally used the method of pulse dosed VGT.

\section{Statistical analysis}

To reliably evaluate the obtained data the methods of variation statistics were used with the calculation of the average indicators $(\mathrm{M})$, their deviations $(\delta)$, and their errors $(\mathrm{m})$. The evaluation of the obtained data was carried out by the Student's reliability criteria. Analytical software: Statistical analysis of data was carried out using SAS ${ }^{\circledR}$ software version 9.3 (SAS inc. Cary, North Carolina, USA), including the statistical database to be evaluated, including all changes, additions, and the receipt and calculation of the variables recorded in this clinical trial.

\section{Results}

Indications for treatment, general recommendations for pharmacotherapy, treatment regimens with the determination of course and daily doses, control of cure, follow-up tactics in the absence of treatment effect were determined according to the Federal Clinical Recommendations of Russian Society of Dermatovenereologists and Cosmetologists (2015). To treat Gonococcal infection, Ceftriaxone was used 1.0 intramuscularly, every 24 hours for 14 days; Mycoureaplasma infection, Jozamycin 500mg orally 3 times a day for 14 days or doxycycline monohydrate $100 \mathrm{mg}$ orally 2 times a day for 14 days; Trichomonas infection, Metronidazole $500 \mathrm{mg}$ orally 3 times a day for 7 days or tinidazole $2.0 \mathrm{mg}$ orally once a day for 3 days; Chlamydial infection, Doxycycline monohydrate $100 \mathrm{mg}$ orally 2 times a day for 14 days or Josamycin 500mg orally 3 times for 14 days; Candidiasis, Fluconazole $150 \mathrm{mg}$ orally once or Itraconazole $200 \mathrm{mg}$ orally once a day for 3 days.

In both groups, a complex treatment of chronic prostatitis with a course of prostate massage No 10 per rectum was performed every other day. Moreover enzyme, vasodilator, vitamin and hepatoprotective medications were administered. The only difference in the main group is, the pulse dosed vacuum gradient therapy was additionally used.

A control laboratory examination performed after the course of therapy completion revealed only 1 case of Chlamydia infection in the main group and 3 cases in the control group (Mycoplasmal, Chlamydial and Ureaplasma infections). Thus, the effectiveness of the etiological cure of patients in the main group was $99.1 \%$, while in the control group it composed $92.5 \%$.

One of the indicators of the partial restoration of the infiltrativesclerotically altered prostate tissue was the detection of hyperechoic regions by transrectal ultrasound investigation. These are areas of fibrosis, the presence of connective tissue. Prior to the treatment of the main group patients, such zones were revealed in 42 cases composing 
$40.0 \%$, in patients of the control group - in 16 cases $(40.0 \%)$. After the treatment such zones according to transrectal ultrasound investigation were detected in the main group in 12 patients, which was $11.4 \%$, and in the control group in 13 patients, composing $32.5 \%$ of the cases. Thus, the application of the pulse dosed VGT in the main group was almost 3 times more effective than in the control group.

The ultrasound dopplerographic examination of the prostate gland in patients with chronic prostatitis revealed the presence of various vascular malformations. For example, the vascular density was assessed, which was $0.87 \pm 0.04$ vessels per 1 sq.cm before the treatment in the main group, and in the control group $0.85 \pm 0.05$ vessels per $1 \mathrm{sq} . \mathrm{cm}$. After the performed therapy, the values of vascular density in the main group were higher by $0.7 \pm 0.02$ and amounted to $1.57 \pm 0.03$. The parameters of vascular density in the control group remained practically unchanged and stopped at the level of $0.85 \pm 0.08$ vessels per 1 sq.cm

Taking into account that the intensity of the medication effect used during the treatment is in direct proportion to its concentration at the site of action, the concentration of doxycycline monohydrate in the blood and in the prostatic secretion was determined 2 hours after taking its daily dose. On the first day of treatment the concentration of doxycycline monohydrate 2 hours after its oral daily intake in a dose of $200 \mathrm{mg}$ in blood plasma and prostatic fluid in both groups were comparable: in the blood of patients in the main group it was $2.2 \pm 0.1 \mu \mathrm{g} / \mathrm{ml}$, in blood of patients in the control group - $2.1 \pm 0.8 \mu \mathrm{g} /$ $\mathrm{ml}$; at the prostatic secretion $-1.4 \pm 0.02 \mu \mathrm{g} / \mathrm{ml}$ and $1.4 \pm 0.06 \mu \mathrm{g} / \mathrm{ml}$, respectively

On day 14 of treatment 2 hours after taking a daily dose of $200 \mathrm{mg}$, the concentrations of doxycycline monohydrate in patients of both groups were as follows: the concentration of the medication in blood plasma was also comparable in both groups - in the main group $2.2 \pm 0.5 \mu \mathrm{g} / \mathrm{ml}$, in the control group was $2.2 \pm 0.3 \mu \mathrm{g} / \mathrm{ml}$. The concentration of doxycycline monohydrate in the prostatic secretion in the main group increased significantly from $1.4 \pm 0.02 \mu \mathrm{g} / \mathrm{ml}$ to $2.0 \pm 0.1 \mu \mathrm{g} / \mathrm{ml}$, i.e. by $0.6 \pm 0.01 \mu \mathrm{g} / \mathrm{ml}$, while in the control group it remained practically at the baseline level of $1.4 \pm 0.08 \mu \mathrm{g} / \mathrm{ml}$.

\section{Discussion}

Early detection of STIs can prevent not only its further spread, transmission to the offspring, but also reduce the risk of developing serious complications that violate reproductive function. The clinical and social importance of STIs lies precisely in the development of complications, because a long asymptomatic course creates favorable conditions for the spread of infection from the lower sections of the urogenital tract to the pelvic organs performing basic reproductive function of the body.

The main method of etiological identification of STIs was the PCR method (polymerase chain reaction). Such modern instrumental and hardware methods of examination of complicated forms of STI were used for clinical diagnostics in this study, as highly informative methods of fiber-optic digital video urethroscopy with computer processing of the obtained data, ultrasound transrectal examination with an assessment of the dynamics of the state of the structure of the prostate tissue and evaluation of the change in blood flow in the prostate gland during the performed treatment.
The main aim of the treatment in our work was not only the eradication of the causative agent of the STI from the patient's organism, but also the complete or partial restoration of the structure, anatomical integrity of the damaged tissues and the physiological function of the prostate gland. Therefore, we were faced with the task of selecting the technology of treatment that would ensure not only the sanitation of the organism from the infectious agent, but also the maximum possible recovery of damaged prostate tissue during inflammation. We chose the method of pulse dosed vacuum gradient therapy. It, due to difference in atmospheric pressure between the environment and the mini pressure chamber, into which the penis was placed, significantly improved blood flow in the prostate gland, which increased the natural metabolism in the affected tissues and increased the concentration of the drug in the inflamed organs, prostate gland.

A large percentage of the failure of etiotropic treatment in the control group can be explained by two main reasons. Firstly, in the control group, where treatment was standard, there was no therapeutic effect aimed at increasing blood flow in the prostate gland, which would accordingly increase the concentration of drugs in the affected area. Secondly, the possibility of bacteria forming a biofilm in epithelium of the ductal system of the prostatic gland, which leads to the persistence of the infection and consequently to the resistance of the causative agent of STI to medications.

Particular attention was paid to the dynamics of the restoration of structural changes in the prostate tissue that were changed during the inflammatory process. After the treatment the normalization of inflammatory and structural changes in prostate tissue in the main group occurred in $83.7 \%$ of cases, and in the control group only in $45.0 \%$. Thus, the use of pulsed dosed VGT in the complex treatment of chronic prostatitis in the main group was almost two times more effective than treatment in the control group without the use of VGT.

Considering that blood and vascular system are the main instruments for medication delivery to the affected organs, we studied the dynamics of blood flow in the organ examined. In this regard, it was necessary to objectively determine the effectiveness of dosed VGT for overcoming the hematoprostatic barrier by medications, i.e. compare the concentration of medication in blood plasma and in prostatic fluid in the main and control groups. The results have shown that pulsed dosed VGT is a non-invasive and accessible tool for targeted medication delivery to target organs, in this case to prostate gland.

\section{Conclusion}

The results of the study showed that the use of pulse dosed vacuum gradient therapy as an additional method in the complex treatment of chronic prostatitis associated with sexually transmitted infections is safe and much more effective than the standard methods of therapy. Moreover, the use of this method allows to partially reconstruct the infiltrative-sclerotically altered prostate tissue, as well as restore vascular disorders, what makes it possible to increase blood flow, and, consequently, to increase the therapeutic concentration of medications and significantly reduce the medications load on the patient's organism. 


\section{Acknowledgements}

This clinical study was supported by Kazan State Medical University, Kazan, Russian Federation.

\section{Conflict of interest}

All authors certify that they have no conflict of interest.

\section{References}

1. Sadretdinov RA, Polunin AA, Voronina LP. Sostojanie mikrososudisto reaktivnosti u besplodnyh i fertil'nyh bol'nyh hronicheskim prostatitom. Vestnik novyh medicinskih tehnologij. 2015;22(4):69.

2. Truhan DI, Makushin DG, Bagisheva NV. Hronicheskij prostatit: aktual'nye voprosy diagnostiki i lechenija na jetape okazanija pervichnoj specializirovannoj i mediko-sanitarnoj pomoshhi. Mezhdunarodnyj zhurnal prikladnyh i fundamental'nyh issledovanij. 2016;6(2):285-291.

3. Belyj LE, Konshin II. Osobennosti narushenij spermatogeneza posle perenesennogo ostrogo jepididimoorhita. Vestnik novyh medicinskih tehnologij. 2013;3:172-174.

4. Segal AS, Dolgopjatov DG, Balashova LD. Antibakterialnaja terapija pri uretritah i uretroprostatitah hlamidijnoj jetiologii. Materialy plenuma Vserossijskogo obshhestva urologov Perm. 2009;126.

5. Polunin AA, Miroshnikov VM, Voronina LP, et al. The relationship between acute inflammatory phase proteins and dysfunction of regional microvascular endothelium in chronic bacterial and congestive prostatitis. Astrahanskij medicinskij zhurnal. 2014;(1):67-72. 